BMJ Paediatrics Open

\section{How boys and testicles wander to surgery: a nationwide cohort study of surgical delay in Sweden}

To cite: Omling E, Bergbrant S, Persson A, et al. How boys and testicles wander to surgery: a nationwide cohort study of surgical delay in Sweden. BMJ Paediatrics Open 2020;4:e000741. doi:10.1136/ bmjpo-2020-000741

European Paediatric Surgery Association (EUPSA) Congress in Belgrade, Serbia, June 2019.

Received 20 May 2020 Revised 20 August 2020 Accepted 25 August 2020

Check for updates

(c) Author(s) (or their employer(s)) 2020. Re-use permitted under CC BY-NC. No commercial re-use. See rights and permissions. Published by BMJ

${ }^{1}$ Pediatric Surgery, Skåne University Hospital Lund, Lund, Sweden

${ }^{2}$ Department of Pediatrics, Lund University Clinical Sciences, Lund, Sweden

${ }^{3}$ GIS Centre, Lund University Lund, Sweden

${ }^{4}$ Department of Physical Geography and Ecosystem Sciences, Lund University, Lund, Sweden

${ }^{5}$ Department of Laboratory Medicine, Lund University, Lund, Sweden

${ }^{6}$ Clinical Studies Sweden, Forum South, Skåne University Hospital Lund, Lund, Skåne, Sweden

Correspondence to Dr Erik Omling; erik.omling@ med.lu.se

\section{ABSTRACT}

Background Early orchidopexy is recommended for cryptorchidism and the surgery is increasingly centralised. The objectives were to determine the incidence, risk factors and if distance to treating hospital impacted on timely treatment of cryptorchidism.

Methods In this observational study, all boys born in Sweden from 2001 to 2014 were followed in national registers to determine the incidence of cryptorchidism by levels of birth-related risk factors and social determinants. Travel time to hospital was used as the primary exposure in multivariable survival analysis, with age at surgery as main outcome.

Results 0 f 748678 boys at risk for cryptorchidism, 7351 were treated and evaluated for timing of surgery (cumulative childhood incidence 1.4\%, $95 \% \mathrm{Cl} 1.3 \%$ to $1.5 \%$ ). The incidence was clearly associated with prematurity and overdue pregnancy (HR for $<32$ weeks 2.77 (95\% Cl 2.39 to 3.21 ); $32-36$ weeks HR $1.36(95 \% \mathrm{Cl}$ 1.24 to 1.49$)$; $>41$ weeks HR $1.19(95 \% \mathrm{Cl} 1.10$ to 1.29$)$ ), low birth weight (<1000 g HR 3.94 (95\% Cl 3.15 to 4.92$)$; $1000-1499$ g HR 3.70 (95\% Cl 3.07 to 4.46); 1500-2500 g HR 1.69 (95\% Cl 1.52 to 1.88)) and intrauterine growth restriction (small for gestational age HR $2.38(95 \% \mathrm{Cl} 2.14$ to 2.65); large for gestational age HR 1.26 (95\% Cl 1.13 to 1.42$)$ ), but not with smoking or maternal age. Each 30 min increase in travel time was associated with a reduced probability of timely treatment ( $\mathrm{HR}$ for being treated by age 3 adjusted for risk factors and socioeconomic determinants: 0.91 (95\% Cl 0.88 to 0.95)). Lower income and financial support were also associated with treatment delays (adjusted HR for lowest income quintile 0.82 (95\% $\mathrm{Cl} 0.72$ to 0.93 ) and for families with financial support 0.85 $(95 \% \mathrm{Cl} 0.73$ to 0.97$))$.

Conclusions Travel distance to treating hospital was associated with delayed treatment. 'Not all those who wander are lost', but these findings suggest a trade-off between centralisation benefits and barriers of geography also in elective paediatric surgery.

\section{INTRODUCTION}

Cryptorchidism is the most common genital anomaly in boys, with a reported prevalence of $1.0 \%-10.7 \%$, depending on population and risk group. ${ }^{1-6}$ Normal testicular descent is completed in the third trimester and there is limited advancement 6 months after birth.
What is known about the subject?

Cryptorchidism should be treated with early corrective surgery, preferably before 18 months of life, to avoid complications such as malignancy and infertility later in life.

- Risk factors for disease include prematurity and low birth weight.

- Paediatric anaesthesia for young children is in creasingly centralised to tertiary centres, while older children can be treated in hospitals closer to where families live.

\section{What this study adds?}

- The age at surgery varied with travel time to the hospital, with less chance of timely treatment for those living further from the hospital.

- These results imply a trade-off between centralisation benefits and geographical access to healthcare.

Lower income and financial support were associated with treatment delays.

Cryptorchid testicles are associated with impaired semen quality, reduced fertility and increased risk of testicular malignancies later in life, ${ }^{7-11}$ and for these reasons most guidelines and screening programmes aim for diagnosis and treatment at 6-18 months of age.$^{12-15}$ Risk factors include preterm birth, low birth weight and intrauterine growth restriction, ${ }^{1451617}$ and genetic or environmental factors may explain some differences in prevalence in various populations. ${ }^{16}$ Recent studies have suggested that maternal smoking and obesity add to this risk, even if such studies have not considered the explanatory effect of prematurity-related risk factors on the common pathway to disease. ${ }^{18} 19 \mathrm{~A}$ few epidemiological studies have claimed that socioeconomic background, rurality and insurance status are associated with delayed treatment. ${ }^{2021}$ However, these studies were either based on population aggregates or 
averages for area of residence rather than individual-level data, or have not shown any clear association with the risk for delay. ${ }^{22-24}$

In Sweden, like many other countries, neonatal surgery and anaesthesia are increasingly centralised to improve surgical outcomes for rare diseases and for the safety of anaesthesia to the youngest. ${ }^{25}$ Current guidelines for the Nordic countries recommend treatment for congenital cryptorchidism to be performed at specialised paediatric surgery departments at $6-12$ months of age ${ }^{12}$ but only a small minority of boys with cryptorchidism are treated at that age. ${ }^{4}$ It is unclear to what extent the centralisation of paediatric surgical care has become a barrier for children with less complicated conditions living far away, and if families tend to wait until their local hospital can help them. No study has investigated how travel time or distance to treatment impacts on delay and timing of surgery for cryptorchidism.

We performed a 14-year national register-based prospective cohort study for all boys in Sweden, with inclusion of individual-level medical and socioeconomic risk factors. The aim of this total population study was to determine incidence and risk factors for cryptorchidism, and to investigate the association between travel time to hospital and age at treatment, adjusted for medical and socioeconomic background.

\section{PATIENTS AND METHODS}

\section{Study design and study population}

This was a total population study of retrospective longitudinal register data. All boys born in Sweden from 1 January 2001 until 31 December 2014 were eligible for inclusion. Study subjects were followed in national healthcare and administrative registers from birth, and they contributed until 31 December 2014 unless censored due to migration, death or outcome. Excluded were children with comorbidities that were likely to influence the standard or timing of surgical treatment (as determined by the EUROCAT list of minor malformations, $\mathrm{n}=607) .{ }^{26}$ Due to the study design, study subjects were not involved in the planning or conduct of the study.

\section{Settings}

The Swedish welfare system covers all citizens, and paediatric healthcare is free of charge, with no direct out-ofpocket expenses. ${ }^{27}$ Screening for cryptorchidism was performed at birth, and at 6 and 18 months of age, as part of the regular healthy child check-ups performed by paediatricians or general practitioners with paediatric interest. Cryptorchidism is treated with an elective surgical procedure, usually performed under general anaesthesia and inguinal nerve block. According to national guidelines, children younger than 12 months should be referred to a dedicated paediatric surgery unit for safe anaesthesia and surgery. ${ }^{12}$ The median age at surgery among Swedish boys has previously been estimated to decrease from just over 6 years in 2001, to just over 3 years in 2014, and the prevalence of cryptorchidism treatment was stable throughout the study period. ${ }^{4}$

\section{Primary and secondary outcomes}

Primary outcome was occurrence and age at surgery for cryptorchidism, and secondary outcome was occurrence and age when diagnosis was first suspected. Date of birth was adjusted for preterm delivery by adding days up to 40 weeks' pregnancy. Age at surgery was determined by the date of surgery. The International Classification of Diseases, version 10 (ICD-10) and Nordic MedicoStatistical Committee Classification of Surgical Procedures were used throughout the study period for coding of diseases and procedures. ${ }^{28}$ Cryptorchidism was defined by any ICD-10 code Q53.0-9 or Q55.0-1 and surgery for cryptorchidism was defined by any of the procedures KFH00, KFH10, JAH01, KFC00, KFC96 or KFD00 added to the ICD code.

\section{Exposure, risk factors and socioeconomic determinants}

Primary exposure was travel time to treating hospital. The most time-efficient way from the population centroid (ages 0-18 years) of each patient's area of residence (small area of market studies) at the time of birth to the geocoordinates of the treating hospital was estimated, considering speed limitations, stop signals, left turns and right turns as they were at the year of birth, and reported in minutes as a continuous variable. Medical risk factors were length of pregnancy ( $<32$ weeks, 32-36 weeks, 37-41 weeks, $>42$ weeks $)$, birth weight $(<1000 \mathrm{~g}, 1000-1499 \mathrm{~g}$, 1500-2499 g, 2500-4200 g, >4200 g), size for gestational age (small, average or large for gestational age), maternal age and smoking status during pregnancy (no smoking, 1-9 cigarettes/day or $>9 /$ day). Socioeconomic determinants included educational level of parents, unemployment, income, social transfers and place of birth. The highest achieved education within the family was categorised either as the completion of compulsory school $(<10$ years), high school $(<13$ years) or higher education $(>12$ years). Unemployment was defined as any parent being registered in the Swedish Unemployment Service 1 year prior to inclusion. Income was determined by the sum of the parents' income after taxations and transfers the year prior to inclusion, to avoid the influence of parental leave on income, and families were categorised in annual income quintiles to adjust for inflation and shifts in taxation and regulations. Social transfers included any governmental financial support the year prior to inclusion. Parents were categorised as being born either in Sweden or elsewhere, and the child could have two, one or no Swedish-born parent.

\section{Data sources and data validity}

The study population was identified in the Swedish Medical Birth Register (MBR). ${ }^{29}$ Birth characteristics were collected from the MBR, and medical records were retrieved from the Swedish National Patient Register (NPR). MBR covers all births in Sweden and NPR covers 
$>99 \%$ of inpatient care and $80 \%-86 \%$ of specialised outpatient care including day surgery in private and public hospitals during the study period. ${ }^{30}{ }^{31}$ The Swedish Multi-Generation Register was used to identify parents in the cohort, and socioeconomic information and parental place of residence were retrieved from the Longitudinal Integration Database for Health Insurance and Labour Market Studies. ${ }^{32} 33$ The Register of the Total Population (Statistics Sweden) provided information on parents' migration status. ${ }^{34}$ Annual data on the Swedish roads and infrastructure were collected from the Sweden's National Road Database. $^{35}$

\section{Statistical analysis}

Descriptive statistics presents the cohort's independent variables as distributed by levels of primary exposure. As we regarded the study population to be restricted in time and space, CIs and $\mathrm{p}$ values were reported as measures of the statistical uncertainty. The cumulative incidence and timing of cryptorchidism diagnosis and treatment were reported as percentages and presented in Kaplan-Meier curves and assessed by log-rank test. P values obtained by $F$-tests assessed the overall contribution of each categorical variable included in the regression models. HRs of each risk factor, adjusted for study year and socioeconomic determinants, were obtained by Cox regression and reported with 95\% CIs. As primary exposure was applicable only for subjects with surgical treatment, a Cox regression model was designed to assess for treatment delay in the subcohort of treated children, with adjustment for year of birth, risk factors and socioeconomic determinants. Time of censoring was set to 3 years of age; an age cut-off chosen as cases of congenital cryptorchidism should have been identified and treated and acquired cryptorchidism should still have limited influence. To assess robustness of results, alternative censoring at 2 and 5 years of age was applied as well. Similarly, travel time was also categorised and included in the model on the nominal scale as a sensitivity analysis of main associations. To assess sensitivity to uncaptured nonlinearity in main associations of travel time, continuous variables were also analysed with cubic splines and $F$-test, and the overall contribution of the variable to the model was assessed with $F$-test. All multivariable Cox regression models were stratified on healthcare region of residence, in order to adjust for clustered data.

\section{Software}

ArcGIS V.10.2 (Environmental Systems Research Institute of Redlands, California) was used to calculate travel times and STATA/SE V.14.1 for Windows was used for statistics. $^{36}$

\section{RESULTS}

Cumulative incidence and timing surgery

Of 748678 boys, 7351 were treated for cryptorchidism and evaluated for timing of surgery (figure 1). The

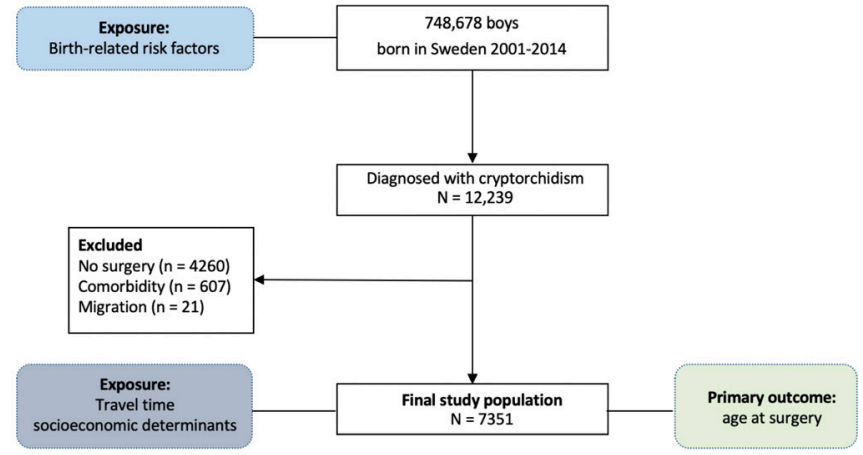

Figure 1 Inclusion and exclusion of Swedish children diagnosed and treated for cryptorchidism.

cumulative incidence of surgically treated cryptorchidism in the oldest birth cohort (2001-2002, followed until 14 years of age) was $1.4 \%$ (95\% CI $1.3 \%$ to $1.5 \%$ ). The estimated travel time from place of residence to treating hospital was $36 \mathrm{~min}$ in mean (SD $58 \mathrm{~min}$ ) and $20 \mathrm{~min}$ in median (IQR 11-38 min). More children travelled longer to the treatment later in the study period (online supplemental eTable 1), and there was also a trend towards earlier diagnosis and treatment later in the study period, in particular after the introduction of national guidelines in 2007 ( $<<0.001$, figure $2 \mathrm{~A}$ and online supplemental eFigure 1).

\section{Risk factors for cryptorchidism}

Prematurity and overdue pregnancy were associated with increased incidence of disease (adjusted for year of birth: $<32$ weeks HR 2.77 (95\% CI 2.39 to 3.21), $\mathrm{p}<0.001$; 32-36 weeks HR 1.36 (95\% CI 1.24 to 1.49), $\mathrm{p}<0.001 ;>41$ weeks HR 1.19 (95\% CI 1.10 to 1.29 ), $\mathrm{p}<0.001$, figure 2B), as were low birth weight (adjusted for year of birth: $<1000$ g HR 3.94 (95\% CI 3.15 to 4.92$)$, $\mathrm{p}<0.001 ; 1000-1499$ g HR 3.70 (95\% CI 3.07 to 4.46$)$, $\mathrm{p}<0.001 ; 1500-2500$ g HR 1.69 (95\% CI 1.52 to 1.88 ), $\mathrm{p}<0.001 ;>4200 \mathrm{~g} \mathrm{HR}$ 1.05 (95\% CI 0.99 to 1.13 ), $\mathrm{p}=0.12$, figure $2 \mathrm{C}$ ) and intrauterine growth restriction (adjusted for year of birth: small for gestational age HR 2.38 (95\% CI 2.14 to 2.65), $\mathrm{p}<0.001$; large for gestational age HR 1.26 (95\% CI 1.13 to 1.42 ), $\mathrm{p}<0.001$, figure $2 \mathrm{D}$ ). Maternal age and smoking status were not associated with the incidence (log rank test $\mathrm{p}=0.42$ and $\mathrm{p}=0.19$, respectively). These results were robust in bivariate models with adjustment for year of birth (online supplemental eFigure 2), and in a multivariable model with adjustment for socioeconomic confounders (figure 3).

\section{Association between travel distance and timing of treatment}

The unadjusted association between travel distance and timing of treatment is presented in online supplemental eFigure 3. Bivariate associational estimates of travel time and of each socioeconomic variable, with adjustment for year of birth only, are presented in online supplemental eFigure 4 . In the multivariable analysis, the probability of timely surgery decreased by each $30 \mathrm{~min}$ increase in travel time (adjusted HR 0.91 (95\% CI 0.88 to 0.95 ), $\mathrm{p}<0.001$; 

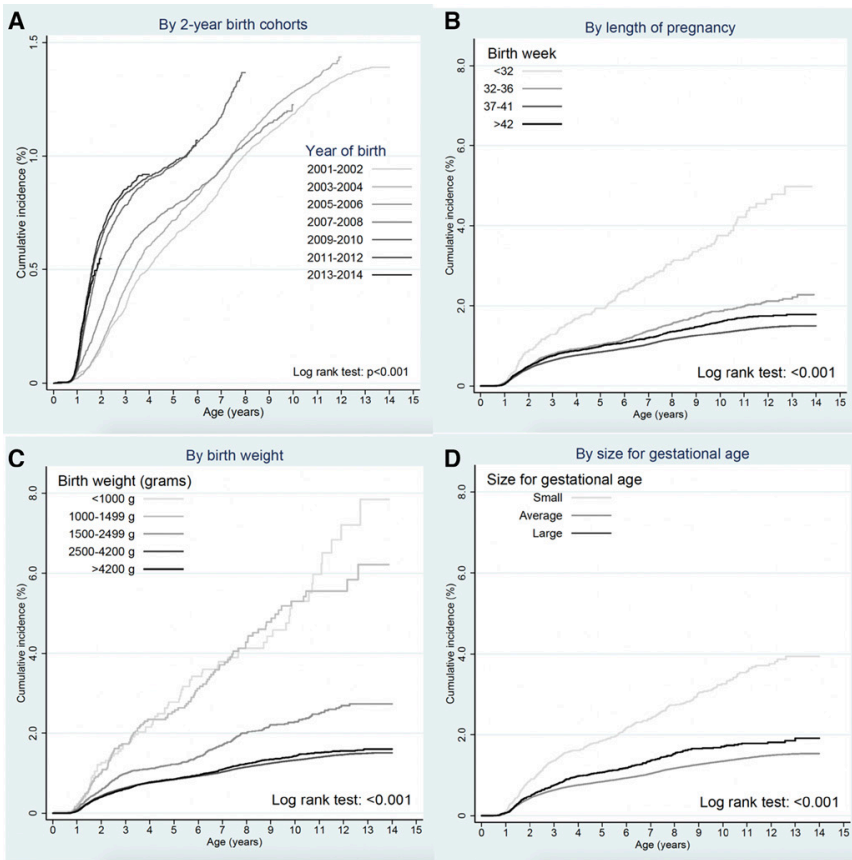

Figure 2 Cumulative incidence of surgery for cryptorchidism among 748678 Swedish boys, by year of birth and risk factors. Follow-up was until end of 2014. Note different scales on vertical axis in (A) and (B)-(D). (A) Age at treatment for 2-year birth cohorts. There was a shift towards earlier treatment after the introduction of Nordic guidelines in 2007. Note the biphasic shape of the curve, indicating an early peak incidence, and a second incidence peak in early school age. (B) By birth week. (C) By birth weight. (D) By size for gestational age.

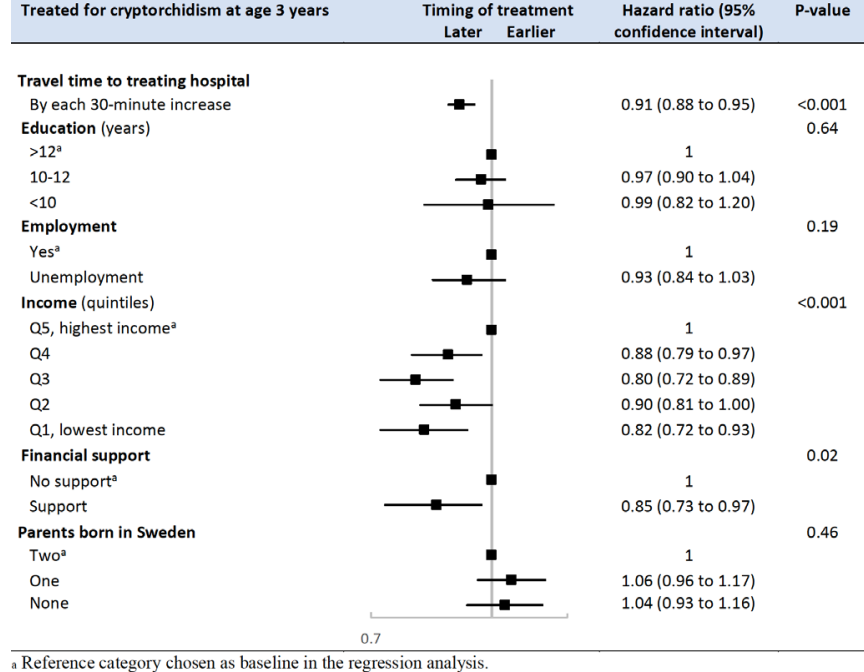

Figure 4 HR of having had surgery at 3 years of age among boys treated for cryptorchidism, by travel time to treating hospital and socioeconomic determinants. Multivariable Cox regression model adjusted for year of birth and medical risk factors (birth week, size for gestational age, maternal smoking and age).

figure 4$)$. Whereas high income $(\mathrm{p}=0.001)$ and absence of social security support (adjusted HR 0.85 (95\% CI 0.73 to 0.97$), \mathrm{p}=0.02$ ) were associated with increased rate of surgical treatment before age of 3 years, no such associations were seen by levels of education, employment or parental migration status (figure 4). The association between travel distance to hospital and treatment age did not change substantially in any of the performed sensitivity analyses (online supplemental appendix pages $7-9$, eFigures 5-7).

\section{DISCUSSION}

In this national birth cohort study of all Swedish-born boys, cumulative incidences of cryptorchidism were determined for established risk factors of disease. The incidence by 14 years of age was $1.4 \%$. Travel distance to the treating hospital was clearly associated with treatment delay, also when medical and socioeconomic factors were adjusted for.

These results underline the considerable national public health implications of screening and treating cryptorchidism in boys, and confirm a remarkable increase in risk for boys born prematurely, with low birth weight or with diverging size for gestational age. The association between travel time and delayed treatment may appear counterintuitive for a non-emergent condition like cryptorchidism. It is possible, however, that some parents could hesitate to accept a long-distance referral with their infant child, or that the result reflects a guideline-awareness gradient within the healthcare system. Regardless, the association delineates a trade-off between centralisation benefits and geographical access in elective surgery for children. Meanwhile, surgical care 
in general, and paediatric surgery in particular, is increasingly centralised; these findings address potential problems with this transition.

The incidences and risk stratification by medical birth determinants reported here are in line with previous studies. ${ }^{1-61617}$ The biphasic pattern of the cumulative incidence seen in figure 2A indicates a second incidence peak in early school age, presumably representing a mix of acquired cryptorchidism and late detected congenital cases. This finding is in line with earlier observations, even if reliable differentiation between acquired and late detected congenital cryptorchidism is not possible from these data. ${ }^{43}$ However, maternal smoking during pregnancy did not add to the risk in our analysis, and the recently reported association of smoking on cryptorchidism risk may have been mediated by imbalances in established birth-related risk factors. ${ }^{19}$

Earlier studies have suggested associations between rural area of residence and treatment delays in cryptorchidism. However, these studies were either based on population aggregates or averages for area of residence rather than individual-level data, or have not shown any clear association with the risk for delay. ${ }^{202223}$ One study has reported increasing waiting times for paediatric surgery in general among patients living further from hospital. ${ }^{37}$ This study confirms that the patient's travel time to elective care, when adjusted for individual-level socioeconomic determinants, does relate to timely treatment. Interestingly, in this context, increasing travel distance was not associated with adverse outcome in paediatric appendicitis, which may reflect the generally shorter distances to emergency hospitals. ${ }^{38} \mathrm{~A}$ few studies of cryptorchidism, in various healthcare systems and populations, have reported treatment delays for children with worse insurance status or lower average income and education in neighbourhood area of residence. ${ }^{21}$ This effect seems context specific, as indicated by a Canadian study showing that average deprivation status and income level in area of residence did not associate with treatment delays in paediatric surgery in general. ${ }^{37}$ In comparison, high family income does seem to increase the probability to be treated timely within the Swedish healthcare system. Overall, however, socioeconomic background seems to be a relative week predictor of treatment delay in Sweden.

\section{Limitations}

This study was based on individual-level healthcare data and administrative records of a national population of children with free access to care. Consequently, the risk for selection bias due to a diversified healthcare system or financial barriers was reduced to a minimum. However, residual selection bias due to referral propensity based on age cannot be ruled out. Further, distinction between congenital and acquired cryptorchidism could not be done, which relates to the interpretation of the cumulative incidence. Due to the study design, causality cannot be claimed. In addition, associations could be susceptible to unmeasured confounding. However, the susceptibility to uncaptured non-linear trends due to the categorisation of variables is likely low, as the main association was unchanged regardless of how continuous variables were treated in the regression model. The accuracy of the administrative registers is expected to be high, yet it is possible that a hidden skewness exists, and most likely such effect would dilute the observed effects. The data sources could not provide adequate data on referral times and waiting times for surgery, and even if date of surgery is considered a reliable outcome measure of treatment delay, deeper understanding of this concept would require a more detailed analysis of the chain of care between screening and surgery. A strength of this study is that travel time to the treating hospital was measured continuously for each treated individual in this cohort. Travel time may be a more realistic measure of geographic access than measures of distance. Yet these are estimates, not exact travel times, as the trip originated at the population centroid of the area of residence rather than the exact home address. Further, a bias may have been introduced in these calculations as all families were expected to have access to a motor vehicle for transportation, even if this might have varied between socioeconomic strata.

\section{CONCLUSION}

This study confirms that the cryptorchidism incidence among boys is tightly linked to prematurity, low birth weight and size for gestational age. The association between travel time to hospital and access to timely treatment for elective surgery in children was measured, with adjustment for socioeconomic determinants on individual level. We conclude that increased travel time was associated with delayed treatment.

Acknowledgements The authors acknowledge Chloe Näslund and Mahnaz Moghaddassi for their contributions with GIS analysis and data management, and the services provided by Statistics Sweden and by the Swedish Board of Health and Welfare in retrieving data.

Contributors EO and LH planned, designed and conceptualised the study, applied for ethical approval, obtained data, performed statistical analyses, interpreted results, drafted and approved the manuscript. JB planned, designed and conceptualised the study, applied for ethical approval, performed statistical analyses, interpreted results and approved the final manuscript. SB planned, designed and conceptualised the study, applied for ethical approval, obtained data, interpreted results and approved the final manuscript. AP conceptualised the study, performed geographic data analysis, interpreted results and approved the final manuscript. All authors approved the final manuscript as submitted and agree to be accountable for all aspects of the work.

Funding This work was supported by the Swedish Society of Medicine (Young Investigator Award), Anna Lisa \& Sven-Eric Lundgren Foundation for Medical Research, and Region Skåne ALF Project and educational grants from Lund University (LH and EO).

Disclaimer The funders were not involved in planning, designing, analysing or interpreting data or in writing the manuscript and the decision to publish the results.

Competing interests None declared.

Patient and public involvement Patients and/or the public were not involved in the design, or conduct, or reporting, or dissemination plans of this research. 
Patient consent for publication Not required.

Ethics approval Approval to access healthcare data of the cohort was obtained from the Ethical Review Board in Lund (2014/791 and 2015/429) and ethical approval to access individual-level socioeconomic and geographic determinants on parents was obtained from the Central Ethical Review Board in Stockholm (0̈ 19-2015), and by ethical vetting at Statistics Sweden. The study was reported in compliance with the STROBE guidelines. It was not possible or appropriate to involve patients and public in the research process.

Provenance and peer review Not commissioned; externally peer reviewed.

Data availability statement Data may be obtained from a third party and are not publicly available. Please contact the corresponding author with requests regarding data access.

Open access This is an open access article distributed in accordance with the Creative Commons Attribution Non Commercial (CC BY-NC 4.0) license, which permits others to distribute, remix, adapt, build upon this work non-commercially, and license their derivative works on different terms, provided the original work is properly cited, appropriate credit is given, any changes made indicated, and the use is non-commercial. See: http://creativecommons.org/licenses/by-nc/4.0/.

ORCID iD

Erik Omling http://orcid.org/0000-0003-0426-9819

\section{REFERENCES}

1 Cortes D, Kjellberg EM, Breddam M, et al. The true incidence of cryptorchidism in Denmark. J Urol 2008;179:314-8.

2 Schneuer FJ, Holland AJA, Pereira G, et al. Age at surgery and outcomes of an undescended testis. Pediatrics 2016;137:e20152768.

3 Acerini CL, Miles HL, Dunger DB, et al. The descriptive epidemiology of congenital and acquired cryptorchidism in a UK infant cohort. Arch Dis Child 2009;94:868-72.

4 Bergbrant S, Omling E, Björk J, et al. Cryptorchidism in Sweden: a nationwide study of prevalence, operative management, and complications. J Pediatr 2018;194:197-203.

5 Berkowitz GS, Lapinski RH, Dolgin SE, et al. Prevalence and natural history of cryptorchidism. Pediatrics 1993;92:44-9.

6 Jensen MS, Olsen LH, Thulstrup AM, et al. Age at cryptorchidism diagnosis and orchiopexy in Denmark: a population based study of 508,964 boys born from 1995 to 2009. J Urol 2011;186:1595-600.

7 Engeler DS, Hösli PO, John H, et al. Early orchiopexy: prepubertal intratubular germ cell neoplasia and fertility outcome. Urology 2000;56:144-8.

8 Lee PA, Coughlin MT. Fertility after bilateral cryptorchidism. evaluation by paternity, hormone, and semen data. Horm Res 2001;55:28-32.

9 Hadziselimovic F, Herzog B. The importance of both an early orchidopexy and germ cell maturation for fertility. Lancet 2001;358:1156-7.

10 Hadziselimovic F, Höcht B, Herzog B, et al. Infertility in cryptorchidism is linked to the stage of germ cell development at orchidopexy. Horm Res 2007;68:46-52.

11 Pettersson A, Richiardi L, Nordenskjold A, et al. Age at surgery for undescended testis and risk of testicular cancer. $N$ Engl J Med Overseas Ed 2007;356:1835-41.

12 Martin Ritzén E, Bergh A, Bjerknes R, et al. Nordic consensus on treatment of undescended testes. Acta Paediatr 2007;96:638-43.

13 Gerharz E, Hoebeke P, Kocvara R, et al. EAU guidelines of pediatric urology. Urology2013:291-303.

14 Ludwikowski B, Becker K, Stein R, et al. Hodenhochstand - Maldescensus testis. AWMF online 2013:1-12. Available: https://www.awmf.org/uploads/tx szleitlinien/006-022I S2k Hodenhochstand Maldescensus-testis 2018-08.pdf [Accessed 21 Nov 2018].

15 Kolon TF, Herndon CDA, Baker LA, et al. Evaluation and treatment of cryptorchidism: AUA guideline. J Urol 2014;192:337-45.

16 Boisen KA, Kaleva M, Main KM, et al. Difference in prevalence of congenital cryptorchidism in infants between two Nordic countries. Lancet 2004;363:1264-9.
17 Sijstermans K, Hack WWM, Meijer RW, et al. The frequency of undescended testis from birth to adulthood: a review. Int $J$ Androl 2008;31:1-11.

18 Arendt LH, Ramlau-Hansen $\mathrm{CH}$, Lindhard MS, et al. Maternal overweight and obesity and genital anomalies in male offspring: a population-based Swedish cohort study. Paediatr Perinat Epidemiol 2017;31:317-27.

19 Kjersgaard C, Arendt LH, Ernst A, et al. Lifestyle in pregnancy and cryptorchidism in sons: a study within two large Danish birth cohorts. Clin Epidemiol 2018;10:311-22.

20 Wagner-Mahler K, Kurzenne J-Y, Delattre I, et al. Prospective study on the prevalence and associated risk factors of cryptorchidism in 6246 newborn boys from NICE area, France. Int $J$ Androl 2011;34:e499-510.

21 Savoie KB, Bachier-Rodriguez M, Schurtz E, et al. Health disparities in the appropriate management of cryptorchidism. J Pediatr 2017;185:187-92.

22 Bayne AP, Alonzo DG, Hsieh MH, et al. Impact of anatomical and socioeconomic factors on timing of urological consultation for boys with cryptorchidism. J Urol 2011;186:1601-5.

23 Springer A, Subramaniam R, Krall C, et al. Orchidopexy patterns in Austria from 1993 to 2009. J Pediatr Urol 2013;9:535-41.

24 Hougaard KS, Larsen AD, Hannerz $\mathrm{H}$, et al. Socio-occupational class, region of birth and maternal age: influence on time to detection of cryptorchidism (undescended testes): a Danish nationwide register study. BMC Urol 2014;14:23.

25 Salazar JH, Goldstein SD, Yang J, et al. Regionalization of pediatric surgery: trends already Underway. Ann Surg 2016;263:1062-6.

26 European Surveillance of Congenital Anomalies. EUROCAT guide 1.4 section 3.2 minor anomalies for exclusion, 2014

27 Anell A, Glenngård AH, Merkur S. Health systems in transition Sweden health system review. Health Syst Transit 2012;14:1-159.

28 Nordic Medico-Statistical Committee (NOMESCO). NOMESCO classification of surgical procedures (NCSP), version 1.16. Copenhagen: Nordic Medico-Statistical Committee (NOMESCO), 2011.

29 Socialstyrelsen (The National Board of Health and Welfare). Swedish medical birth register n.d. Available: http://www. socialstyrelsen.se/register/halsodataregister/medicinskafodelsereg istret/inenglish

30 Ludvigsson JF, Andersson E, Ekbom A, et al. External review and validation of the Swedish national inpatient register. BMC Public Health 2011:11:1-16.

31 Socialstyrelsen. Kodningskvalitet I patientregistret Ett nytt verktyg för ATT mäta kvalitet 2013;55

32 Statistiska centralbyrån (Statistics Sweden). Multi-generation register n.d. Available: https://www.scb.se/vara-tjanster/bestallamikrodata/vilka-mikrodata-finns/individregister/flergenerationsr egistret/ [Accessed 5 Jan 2019]

33 Statistiska centralbyrån (Statistics Sweden). Longitudinal integration database for health insurance and labour market studies (LISA) n.d. Available: https://www.scb.se/en/services/guidance-for-researchersand-universities/vilka-mikrodata-finns/longitudinella-register/ longitudinal-integrated-database-for-health-insurance-and-labourmarket-studies-lisa/ [Accessed 13 May 2019].

34 Statistiska centralbyrån (Statistics Sweden). Population by region, marital status, age and sex. Year 1968 - 2014. n.d. Available: http://www.statistikdatabasen.scb.se/pxweb/en/ssd/?rxid= e0690a76-b047-42b0-96f2-7b7c9125c5f7 [Accessed 23 Oct 2018]

35 Trafikverket. Road data overview. Borlänge, Sweden, 2015

36 Environmental Systems Research Institute. ArcGIS 10.3.1, 2015.

37 Szynkaruk M, Stephens D, Borschel GH, et al. Socioeconomic status and wait times for pediatric surgery in Canada. Pediatrics 2014;134:e504-11

38 Omling E, Salö M, Saluja S, et al. Nationwide study of appendicitis in children. BJS 2019;106:1623-31.

39 von Elm E, Altman DG, Egger M, et al. The strengthening the reporting of observational studies in epidemiology (STROBE) statement: guidelines for reporting observational studies. Strobe statement 2007:1-2. Available: http://www.equator-network.org/ reporting-guidelines/strobe/ [Accessed 7 Mar 2020]. 